\title{
Validation of Ozone Monitoring Instrument (OMI) ozone profiles and stratospheric ozone columns with Microwave Limb Sounder (MLS) measurements
}

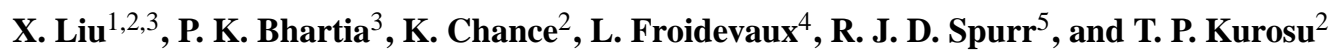 \\ ${ }^{1}$ Goddard Earth Sciences and Technology Center, University of Maryland, Baltimore County, Baltimore, Maryland, USA \\ ${ }^{2}$ Harvard-Smithsonian Center for Astrophysics, Cambridge, Massachusetts, USA \\ ${ }^{3}$ NASA Goddard Space Flight Center, Greenbelt, Maryland, USA \\ ${ }^{4}$ NASA Jet Propulsion Laboratory, Pasadena, California, USA \\ ${ }^{5}$ RT Solutions Inc., Cambridge, Massachusetts, USA
}

Received: 15 September 2009 - Published in Atmos. Chem. Phys. Discuss.: 23 November 2009

Revised: 6 March 2010 - Accepted: 9 March 2010 - Published: 12 March 2010

\begin{abstract}
We validate OMI ozone profiles between 0.22 $215 \mathrm{hPa}$ and stratospheric ozone columns down to $215 \mathrm{hPa}$ (SOC215) against v2.2 MLS data from 2006. The validation demonstrates convincingly that SOC can be derived accurately from OMI data alone, with errors comparable to or smaller than those from current MLS retrievals, and it demonstrates implicitly that tropospheric ozone column can be retrieved accurately from OMI or similar nadir-viewing ultraviolet measurements alone. The global mean biases are within $2.5 \%$ above $100 \mathrm{hPa}$ and $5-10 \%$ below $100 \mathrm{hPa}$; the standard deviations of the differences $(1 \sigma)$ are $3.5-5 \%$ between $1-50 \mathrm{hPa}, 6-9 \%$ above $1 \mathrm{hPa}$ and $8-15 \%$ below $50 \mathrm{hPa}$. OMI shows some latitude and solar zenith angle dependent biases, but the mean biases are mostly within 5\% and the standard deviations are mostly within 2-5\% except for low altitudes and high latitudes. The excellent agreement with MLS data shows that OMI retrievals can be used to augment the validation of MLS and other stratospheric ozone measurements made with even higher vertical resolution than that for OMI. OMI SOC215 shows a small bias of $-0.6 \%$ with a standard deviation of $2.8 \%$. When compared as a function of latitude and solar zenith angle, the mean biases are within $2 \%$ and the standard deviations range from 2.1 to $3.4 \%$. Assuming $2 \%$ precision for MLS SOC215, we deduce that the upper limits of random-noise and smoothing errors for OMI SOC215 range from $0.6 \%$ in the southern tropics to $2.8 \%$ at northern middle latitudes.
\end{abstract}

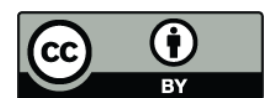

Correspondence to: $\mathrm{X}$. Liu (xliu@cfa.harvard.edu)

\section{Introduction}

We have retrieved ozone profiles from Ozone Monitoring Instrument (OMI) ultraviolet (UV) radiances using the optimal estimation technique (Liu et al., 2005, 2010). Total, stratospheric, and tropospheric ozone columns (OC, SOC, and TOC) are integrated directly from the retrievals. These retrievals constitute a unique dataset to study the spatiotemporal distribution of ozone not only due to information spanning the stratosphere and troposphere, but also to high precision, accurate estimates of OC, SOC, and TOC and OMI's high spatial resolution and daily global coverage. Our dataset complements ozone measurements from the other three instruments on the Aura satellite.

The Microwave Limb Sounder (MLS), also on board the Aura satellite, measures stratospheric ozone profiles with a vertical resolution of $\sim 3 \mathrm{~km}$. Its ozone products have been extensively validated (Jiang et al., 2007; Froidevaux et al., 2008; Livesey et al., 2008). Thus, MLS provides an excellent source to validate our OMI retrievals. In additional to evaluating the OMI/MLS consistency, the close OMI/MLS collocation can significantly minimize the effects of spatiotemporal variability on the comparison, and allow us to evaluate the precision of both measurements. The higher vertical resolution of MLS ozone profiles also allows us to evaluate OMI smoothing errors due to the coarser vertical resolution in the retrievals.

Another motivation for validating OMI retrievals with MLS data is that MLS SOC has been combined with OMI OC to derive TOC. The key to determining TOC from the Tropospheric Ozone Residual (TOR) methods is to obtain

Published by Copernicus Publications on behalf of the European Geosciences Union. 
SOC accurately, since OC itself has been retrieved accurately from the Total Ozone Mapping Spectrometer (TOMS) instruments since 1978. Prior to the launch of Aura, most of the TOC products from TOR methods were monthly means in the tropics. This is largely because of the poor spatiotemporal resolution/coverage or inadequate accuracy in coincidently-measured SOC data and the large geophysical variability in SOC at higher latitudes. With the launch of Aura, SOC can be made from MLS with a precision of $2 \%$ (4 DU) (Froidevaux et al., 2008), simultaneously with OC from OMI. Global distributions of TOC have been derived daily from OMI and MLS data, with the use of linear interpolation (Ziemke et al., 2006), potential vorticity mapping (Yang et al., 2007), trajectory mapping (Schoeberl et al., 2007), or data assimilation (Stajner et al., 2008) to improve the horizontal coverage of MLS observations.

It is generally considered that accurate measurements of SOC by a limb-viewing instrument are necessary to derive daily global distribution of TOC. However, we have shown that SOC can be directly retrieved from hyperspectral UV radiances with retrieval errors (root sum square of randomnoise and smoothing errors) of 1.5-4 DU (Liu et al., 2005, 2010), values that are better than or at least comparable to those from current MLS SOC. It has been difficult to validate satellite retrievals to this level of accuracy, due to the lack of closely collocated measurements and the large geophysical variability in SOC. For example, Froidevaux et al. (2008) and Jiang et al. (2007) showed that the standard deviations of the differences between MLS and Stratospheric Aerosol and Gas Experiment (SAGE)/ozonesonde SOC are 5\% (16 DU)/11\% (30 DU), much larger than the MLS uncertainty estimate of $2-3 \%$. The intercomparison of closely collocated OMI and MLS SOC allows us to improve the characterization of SOC from both instruments. It also serves as an implicit validation of our TOC retrievals, since OC can be derived accurately from nadir-viewing backscattered ultraviolet radiance spectra using our retrieval algorithm (Liu et al., 2005, 2010).

The present paper is the first validation sequel to the paper by Liu et al. (2010). It focuses on validation of OMI stratospheric ozone profiles and SOC with MLS data to demonstrate that stratospheric ozone profiles can be retrieved accurately from OMI, and SOC can be retrieved from OMI with retrieval errors comparable to or smaller than current limb measurements. In separate papers, we will validate our retrievals against ozonesonde observations and OMI/MLS tropospheric ozone columns as well as operational total ozone products. This paper is organized as follows: after a brief introduction to the OMI and MLS instruments and their ozone profile retrievals in Sect. 2, we compare the retrieved ozone profiles and SOC with MLS data in Sect. 3. Section 4 summarizes this study.

\section{Satellite instruments and ozone profile retrievals}

The NASA Earth Observing System (EOS) Aura satellite was launched on 15 July 2004 into a $705-\mathrm{km}$ sunsynchronous polar orbit with a $98.2^{\circ}$ inclination and an equator-crossing time of $\sim 13: 45$ (ascending node) (Schoeberl et al., 2006). Aura makes comprehensive measurements of stratospheric and tropospheric composition from four instruments, including OMI and MLS.

\subsection{OMI and ozone profile retrievals from OMI}

OMI is a Dutch-Finnish built nadir-viewing pushbroom $\mathrm{UV} /$ visible instrument. It measures backscattered radiances in three channels covering the $270-500 \mathrm{~nm}$ wavelength range (UV-1: $270-310 \mathrm{~nm}, \mathrm{UV}-2$ : $310-365 \mathrm{~nm}$, visible: $350-$ $500 \mathrm{~nm}$ ) at spectral resolutions of $0.42-0.63 \mathrm{~nm}$ (Levelt et al., 2006). OMI has a wide field of view $\left(114^{\circ}\right)$ with a crosstrack swath of $2600 \mathrm{~km}$. Measurements across the track are binned to 60 positions for UV-2 and visible channels and 30 positions for the UV-1 channel (due to weaker signals). This results in daily global coverage with a spatial resolution of $13 \mathrm{~km} \times 24 \mathrm{~km}$ (along $\times$ across track) at the nadir position for $\mathrm{UV}-2$ and visible channels, and $13 \mathrm{~km} \times 48 \mathrm{~km}$ for the UV- 1 channel. It measures $\mathrm{OC}$, ozone profile, and the total abundances of other trace gases (e.g., $\mathrm{NO}_{2}, \mathrm{SO}_{2}, \mathrm{HCHO}, \mathrm{BrO}$, $\mathrm{CHOCHO}, \mathrm{OClO}$ ), as well as UV-absorbing aerosols and clouds.

Profiles of partial ozone column densities in 24 layers from the surface to $\sim 60 \mathrm{~km}$ are retrieved from OMI radiances in the spectral region $270-330 \mathrm{~nm}$ using the optimal estimation technique. The retrievals are constrained with month- and latitude-dependent climatological a priori ozone profiles and corresponding variances derived from 15 years of ozonesonde and SAGE data (McPeters et al., 2007) under consideration of OMI random-noise measurement errors. OMI radiances are pre-calibrated based on two days' average radiance differences in the tropics between OMI observations and simulations with zonal mean MLS data for pressure $<215 \mathrm{hPa}$ and climatological ozone profiles for pressure $>215 \mathrm{hPa}$. This "soft-calibration" varies with wavelength and cross-track positions, typically from $-6 \%$ to $7 \%$ (Liu et al., 2010). However, it is applied independent of space and time.

Retrievals contain $\sim 6-7$ degrees of freedom for signal (Rodgers, 2000), with 5-6.7 in the stratosphere and 0-1.5 in the troposphere. Vertical resolution generally varies from $\sim 7-11 \mathrm{~km}$ in the stratosphere to $\sim 10-14 \mathrm{~km}$ in the troposphere (when there is adequate retrieval sensitivity to tropospheric ozone) (Liu et al., 2010). Retrieval random-noise errors (i.e., precisions) typically range from $0.5-2 \%$ in the middle stratosphere to as much as $10 \%$ in the lower stratosphere and troposphere. Retrieval errors (i.e., root sum square of random-noise and smoothing errors) are dominated by smoothing errors due to coarse vertical resolution, and 
generally vary from $0.8-6 \%$ in the middle stratosphere to $6-35 \%$ in the troposphere. OC, SOC, and TOC can be accurately retrieved, with retrieval errors typically within $0.2-$ 4, 1.5-4, 2-5 DU, respectively, under solar zenith angles (SZAs) less than $80^{\circ}$. Errors due to forward model and forward model parameter assumptions are generally much smaller compared to the smoothing errors. The main sources of these errors include systematic errors in temperature and cloud-top pressure. Systematic measurement errors (especially those varying with wavelengths) are the most difficult to estimate largely due to lack of full understanding of the OMI instrument calibration. We will determine systematic measurement errors remaining after soft calibration through intercomparison with other measurements. For more details, see the description in Liu et al. (2010).

\subsection{MLS and ozone profile retrievals from MLS}

MLS is a forward-looking microwave limb sounder that measures thermal emission at millimeter and sub-millimeter wavelengths (Waters et al., 2006). It takes measurements along-track (adjacent Aura orbits are $\sim 24.7^{\circ}$ longitude apart at the equator), and performs 240 limb scans per orbit with a footprint of $\sim 6 \mathrm{~km}$ across-track and $\sim 200 \mathrm{~km}$ along-track, providing $\sim 3500$ profiles during both day and night. Measurements are taken $\sim 7 \mathrm{~min}$ ahead of OMI for the same locations during daytime orbital tracks. MLS measures vertical profiles of mesospheric, stratospheric, and upper tropospheric temperature, ozone, $\mathrm{CO}, \mathrm{H}_{2} \mathrm{O}$, and many other constituents (Waters et al., 2006).

The MLS ozone used to validate OMI retrievals is the version 2.2 standard ozone product retrieved from radiance measurements near $240 \mathrm{GHz}$. It has been extensively characterized and validated (Jiang et al., 2007; Froidevaux et al., 2008; Livesey et al., 2008). The vertical resolution is estimated to be $2.7-3 \mathrm{~km}$ from the upper troposphere to the middle mesosphere and the horizontal resolution is about 200$300 \mathrm{~km}$ (along the track). The precision is estimated to be $10-30 \%(0.3 \mathrm{ppmv})$ at $0.2-1 \mathrm{hPa}, 2-5 \%(0.1-0.2 \mathrm{ppmv})$ at $2-$ $46 \mathrm{hPa}$, and $0.04 \mathrm{ppmv}(2-100 \%$ since the ozone values vary a lot) at $68-215 \mathrm{hPa}$. The precision of the ozone column (for a single profile) down to $100-215 \mathrm{hPa}$ is about $2 \%$ (with a conservative estimate of $3 \%$ ). The systematic uncertainty is estimated to be $\sim 5-10 \%$ in most of the stratosphere, about $20 \mathrm{ppbv}+5-20 \%$ in the $100-215 \mathrm{hPa}$ region.

\section{Comparison with MLS}

To validate our OMI retrievals with MLS data, we perform almost one year (347 days of MLS data available at the time of comparison) of OMI retrievals collocated with daytime MLS data for 2006; the center of an MLS footprint is taken to lie within a collocated OMI footprint. The spatial difference arises from unequal horizontal resolutions: $13 \mathrm{~km} \times 48 \mathrm{~km}$ for OMI vs. $200 \mathrm{~km} \times 6 \mathrm{~km}$ for MLS. The time difference is $7 \mathrm{~min}$ apart. The OMI across-track position collocated with MLS data varies with latitude, ranging from UV-1 position 20 in the tropics to position 15 at high latitudes. We screen the MLS data following all the criteria recommended in Froidevaux et al. (2008). The vertical range recommended for using MLS data is $0.02-215 \mathrm{hPa}$. The top layer in our retrieval is a broad layer from $0.35 \mathrm{hPa}$ to the top of atmosphere. To avoid large interpolation errors in this broad layer, we compare ozone profiles from 0.22 to $215 \mathrm{hPa}$. We use only those MLS profiles with valid entries in this pressure range (after data screening). For OMI, we use retrievals with $\mathrm{SZA}<88^{\circ}$, with relative mean fitting residuals (the ratio of fitting residuals to measurement errors) $<1.5$, and with average fitting residuals $<2.5 \%$ (filter $\sim 5 \%$ of the OMI measurements, but only $\sim 2 \%$ for $\mathrm{SZA}<75^{\circ}$ ). Clouds are not filtered because we are comparing stratospheric ozone and filtering OMI cloudy pixels only improves slightly the overall comparison.

\subsection{Comparison of ozone profiles}

We first compare OMI retrievals with original MLS profiles on the MLS grid between $0.22-215 \mathrm{hPa}$. MLS ozone profiles in volume mixing ratio (at each pressure level) are integrated to partial ozone columns for each layer using a code provided by the MLS team. OMI retrievals are then interpolated to partial ozone columns at the MLS layers. Figure 1 (left) compares OMI and MLS partial ozone columns at six selected layers for one orbit of retrievals on 11 July 2006. OMI retrievals generally track MLS ozone very well, with much better correspondence compared to the a priori values, although large differences can occur.

OMI and MLS differences could be due to several sources. These include (i) smoothing errors in OMI data relative to MLS data, (ii) precision and systematic measurement errors in both OMI and MLS, (iii) forward model parameter errors from both OMI and MLS data, (iv) geophysical variability and OMI/MLS horizontal smoothing errors due to different footprints (OMI pixel size is smaller by a factor of $\sim 15$ along the track but larger by a factor of $\sim 8$ across the track), and (v) interpolation errors due to different vertical discretizations. Smoothing errors from OMI are estimated statistically in our retrievals, but can also be estimated directly using coincident MLS data by assuming the MLS data to be the truth ( $\boldsymbol{X}_{\text {MLS }}$ ), and simulating the expected retrieved ( $\boldsymbol{X}_{\text {MLS }}^{\prime}$ ) from our OMI algorithm with the use of OMI averaging kernels (AKs) to degrade MLS profiles to the OMI vertical resolution (Rodgers, 2000):

$\boldsymbol{X}_{\mathrm{MLS}}^{\prime}=\boldsymbol{X}_{a}+\mathbf{A}\left(\boldsymbol{X}_{\mathrm{MLS}}-\boldsymbol{X}_{a}\right)$

where $\boldsymbol{X}_{a}$ is the a priori ozone profile used in OMI retrievals and $\mathbf{A}$ is the AK matrix. The differences between $\boldsymbol{X}_{\text {MLS }}^{\prime}$ and $\boldsymbol{X}_{\text {MLS }}$ are the estimated OMI smoothing errors with relative to MLS data, although we note that errors in MLS data could 

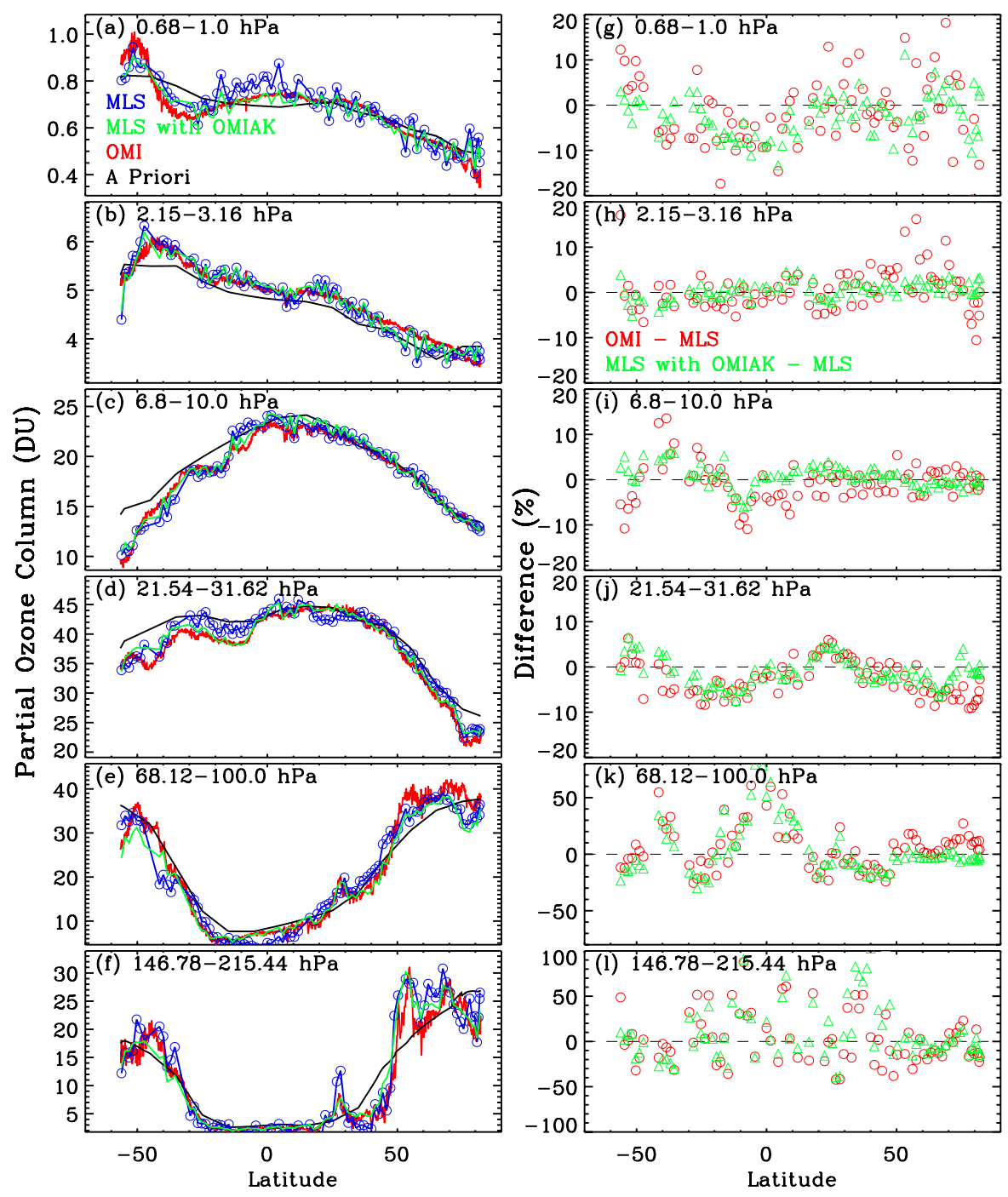

Fig. 1. (a-f) Comparison of one orbit (ascending part) of OMI retrievals (red) along the MLS track on 11 July 2006, with a priori values (black), coincident MLS retrievals (blue) and MLS retrievals convolved with OMI averaging kernels (green) at six MLS layers as a function of latitude. (g-l) Corresponding relative differences (red) between OMI and MLS retrievals defined as (OMI - MLS)/MLS·100\%, and smoothing errors (green) in OMI retrievals estimated by assuming MLS data as the truth.

affect these estimates. To convolve MLS ozone profiles with OMI AKs, MLS partial ozone columns above $215 \mathrm{hPa}$ are complemented with OMI retrievals below $215 \mathrm{hPa}$, and interpolated to the corresponding OMI retrieval grid. After convolving these transformed MLS profiles with OMI AKs using Eq. (1), we interpolate them back to the original MLS retrieval grid.

In addition to comparison with original MLS profiles, we also compare OMI with convolved MLS ozone profiles using Eq. (1). Although this process will not remove the total OMI smoothing errors, it removes the OMI smoothing error-related component of the differences between OMI and MLS profiles and allows us to better identify other sources of OMI/MLS errors. The left panel of Fig. 1 also shows the convolved MLS values (green). We can see that they generally agree better with OMI values than the original MLS data. The right panel of Fig. 1 shows the relative OMI/MLS differences (red circles) as well as smoothing errors (green triangles). For some layers, these two symbols follow each other closely, indicating that the differences are likely due to OMI smoothing errors. The relative differences are sometimes very large (3500\% in worst case) because of small MLS values in the tropical upper troposphere and lower stratosphere, which leads to unrealistic statistics. Therefore, we use the OMI climatological a priori values as the denominator in subsequent results and figures when defining the relative OMI/MLS profile difference at each layer: (OMIMLS)/OMI a priori $\cdot 100 \%$. The statistics are not affected 
significantly by the choice of denominator for layers above $61.8 \mathrm{hPa}$.

The left panel of Fig. 2 shows some examples of mean profile comparison between OMI and original/convolved MLS profiles for five latitude bands. Notably at high latitudes, OMI shows some positive biases over altitudes of maximum ozone density and some negative biases below $100 \mathrm{hPa}$. The right panel shows the difference between OMI and MLS data. The mean differences are generally within $10 \%$ with some large differences in the upper stratosphere, below $100 \mathrm{hPa}$, and mid-stratosphere of high latitudes. The convolution of MLS data with OMI AKs clearly improves the OMI/MLS consistency.

Figure 3 shows the global average profile comparison between OMI and MLS. When compared with the original MLS profiles (blue lines), OMI agrees with MLS to within $4 \%$ from $0.5-100 \mathrm{hPa}$ except for positive biases of $5-10 \%$ above $0.5 \mathrm{hPa}$ and negative biases of $10-15 \%$ below $100 \mathrm{hPa}$. The standard deviations are within 4-6\% from $1.5-32 \mathrm{hPa}$, increasing to $13 \%$ for the top layer and to $36 \%$ for the bottom layer. OMI retrievals show improvement in mean biases over the a priori values (black lines) at most altitudes above $100 \mathrm{hPa}$. In addition, OMI retrievals show significant reduction in variances over the a priori variances, by $20-73 \%$ except for the top two layers, where the standard deviations are slightly larger than those for the differences between a priori and original MLS profiles. The smaller standard deviations for a priori profiles likely indicate that combined errors from OMI and MLS exceed the natural variability of ozone. The purple dashed line shows the combined MLS precision and OMI retrieval errors (random-noise and smoothing errors). These predicted errors are significantly smaller than the standard deviations of the differences in the upper troposphere and lower stratosphere mainly due to differences in smoothing errors between OMI estimates and those derived from Eq. (1) as discussed in the next paragraph; they are significantly larger at high altitudes likely due to the overestimate of MLS precision (also discussed below).

The mean smoothing errors (green lines), estimated by assuming MLS data as the truth, are generally within $2 \%$ except for the top two $(\sim 8 \%)$ and bottom two $(\sim-6 \%)$ layers. The standard deviations of the smoothing errors are 2 $6 \%$ from $0.5-50 \mathrm{hPa}$, increasing to $\sim 8 \%$ for the top two layers and to $30 \%$ for the bottom layer. The smoothing errors dominate OMI/MLS variances over the pressure range of 22$215 \mathrm{hPa}(45-70 \%)$ and can account for $20-40 \%$ of variances at other altitudes. These errors are generally consistent with statistically estimated errors (dashed orange line) from the retrievals except below $\sim 50 \mathrm{hPa}$, where OMI estimates are significantly smaller. Differences due to distinct spatiotemporal footprints and OMI/MLS systematic errors might contribute to larger MLS-derived smoothing errors. In addition, OMI estimates might be underestimated in the lower stratosphere and upper troposphere due to the use of zonal mean climatological a priori information.
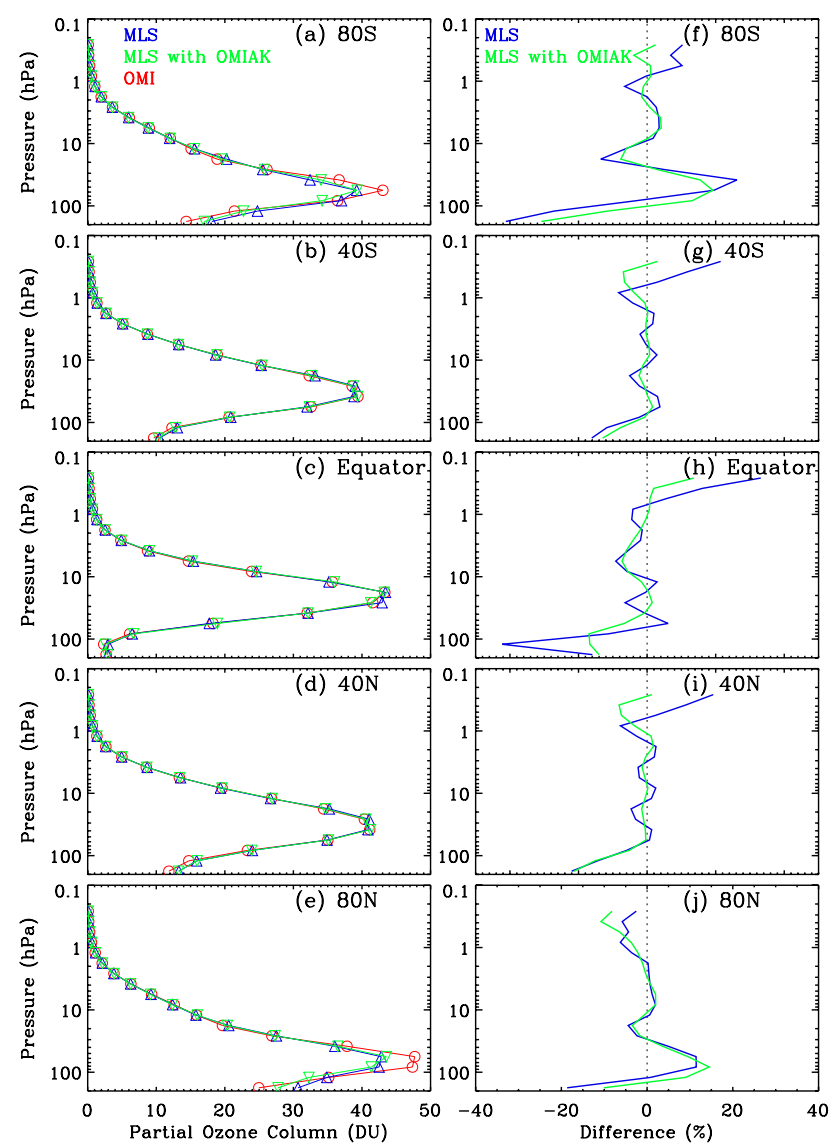

Fig. 2. (Left) Comparison of mean MLS (blue), MLS convolved with OMI averaging kernels (green), and OMI (red) in each MLS layer for five $5^{\circ}$-latitude bands. (Right) Corresponding differences (OMI - MLS) between OMI and MLS (blue)/MLS convolved with OMI averaging kernels (green).

After smoothing errors are removed (red lines), OMI retrievals show excellent agreement (within 2.5\%) with MLS data between $0.22-100 \mathrm{hPa}$. Below $100 \mathrm{hPa}$, OMI has negative biases of $5-10 \%$ compared to MLS. This negative bias is not entirely from OMI, because MLS ozone has been found to have some positive biases in this altitude range relative to other correlative measurements (Froidevaux et al., 2008). The standard deviations are $3.5-5 \%$ from $1-50 \mathrm{hPa}$, 6-9\% for upper layers and 8-15\% for lower layers. Because smoothing errors are largely removed, these standard deviations result mainly from the remaining sources of errors. The pink line in Fig. 3b shows the combined precision averaged from individual OMI and MLS retrievals, in which MLS precision (random error) is reduced by square root of 2 to account for the average of MLS values at two pressure levels to compute the mean value at a layer. It is $2-4 \%$ from $2-68 \mathrm{hPa}$, increasing to $23 \%$ for upper layers and to $18 \%$ for lower layers; the large precisions outside the $3-68 \mathrm{hPa}$ are mainly from MLS data, since OMI precision are typically 

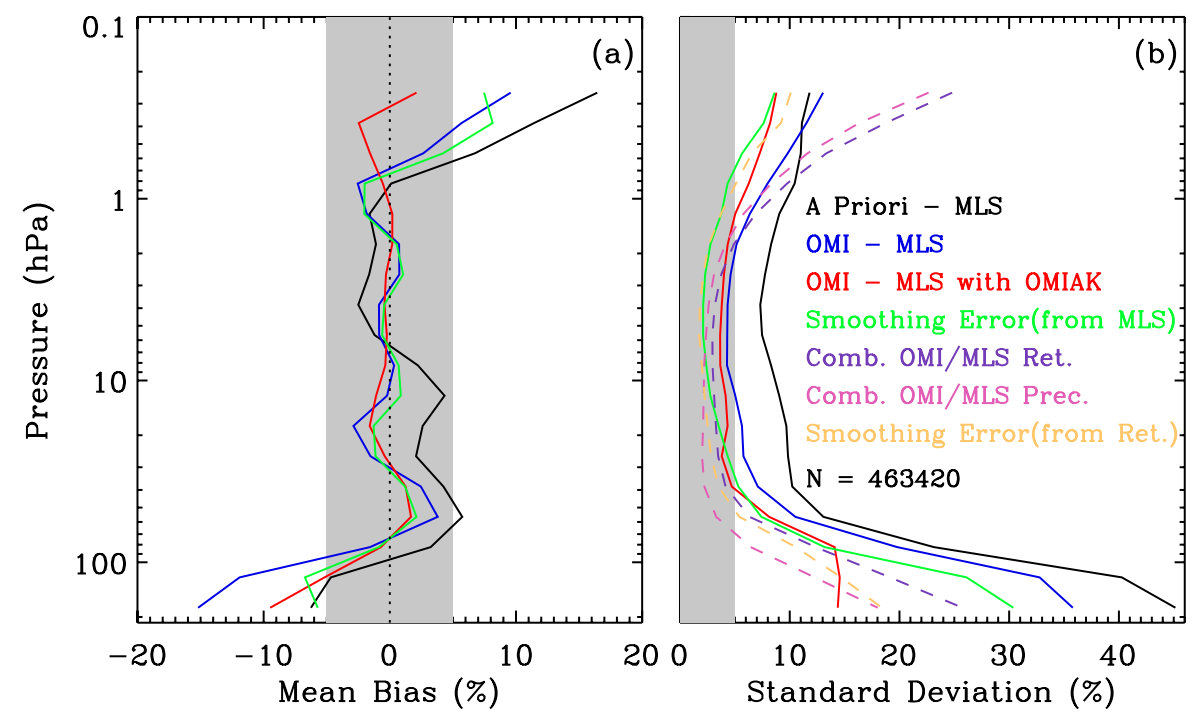

Fig. 3. Mean biases at each MLS layer (a) and corresponding $1 \sigma$ standard deviations of the differences (b) between OMI and MLS profiles (OMI - MLS) from $0.22-215 \mathrm{hPa}$ during 2006. The black and blue lines compare a priori/OMI retrievals and original MLS profiles. The red lines are similar to the blue lines, except that MLS profiles are convolved with OMI averaging kernels. The green lines show OMI smoothing errors estimated by assuming MLS data as the truth. The purple, pink, and orange dashed lines in (b) show the combined OMI retrieval errors and MLS precision and the combined precision of OMI and MLS data, estimated OMI smoothing errors, respectively. The shaded area indicates $\pm 5 \%$.

within $6 \%$ at these altitudes. Note that the combined precision is much larger than values indicated by the red line for the few top layers $(<0.7 \mathrm{hPa})$, suggesting that MLS precision is overestimated at these altitudes. From the square root of the squared differences of OMI/MLS standard deviations (red line) and the combined precision, we can estimate that the uncertainties of the OMI/MLS differences due to the remaining sources of errors (i.e., OMI/MLS systematic measurement errors, forward model and parameter errors, geophysical variability, interpolation errors) are $1-4 \%$ for $3-50 \mathrm{hPa}$ and $7-12 \%$ for $50-147 \mathrm{hPa}$.

Figure 4 shows the mean biases and standard deviations of the differences between OMI and MLS ozone profiles as functions of latitude. The patterns are similar to blue lines in Fig. 3 except for high latitudes, where there are positive biases of 6-12\% in the pressure range $20-70 \mathrm{hPa}$ and the standard deviations are higher than those at lower latitudes. Figure 5 is similar to Fig. 4 except for convolved MLS profiles. As in Fig. 3, the convolution reduces the oscillations in the middle stratosphere and the negative biases at low altitudes, and removes the positive biases at high altitudes. Figure 6 shows comparison similar to Fig. 5, but this time expressed as functions of altitude and SZA for the Southern and Northern Hemispheres, respectively. After the convolution of MLS profiles, the mean biases are mostly within $5 \%$ except for negative biases of $8-16 \%$ in the lowest $1-3$ layers and northern high latitude upper stratosphere, and positive biases of $6-15 \%$ at high latitudes and large SZAs; the standard deviations of the biases are mostly within $2-5 \%$ except for values of $8-19 \%$ in the lowest $3-4$ layers and in the high latitude upper stratosphere. Larger standard deviations at higher latitudes/SZAs and lower altitudes in these figures reflect the combination of larger retrieval errors and greater geophysical variability.

We can see that the mean biases vary with latitude and SZA and there are larger biases at high latitudes/SZAs. Also note that the bias patterns are quite symmetric between the two hemispheres despite different ozone fields, which suggests that these biases are likely caused by SZA-dependent errors such as errors due to OMI straylight errors and radiative transfer calculation errors. In addition, OMI still shows some systematic cross-track position dependent biases. For OMI/MLS coincidences, the OMI cross-track position varies from UV-1 position 20 in the tropics to UV-1 position 15 , cross-track position-dependent biases in our OMI retrievals can be up to 5\% in the upper troposphere and lower stratosphere and within a few percents at higher altitudes. These errors will also contribute to these overall OMI/MLS biases.

The intercomparison with MLS data improves the characterization of MLS ozone by reducing MLS's uncertainty estimates. For example, the standard deviations of the OMI/MLS differences, especially after accounting for the coarser vertical resolution in OMI data using OMI AKs, are significantly smaller than those between MLS and other correlative measurements used in MLS validation including SAGE-II, HALOE (Halogen Occultation Experiment), ACEFTS (Atmospheric Chemistry Experiment Fourier Transform Spectrometer), POAM-III (Polar Ozone and Aerosol 

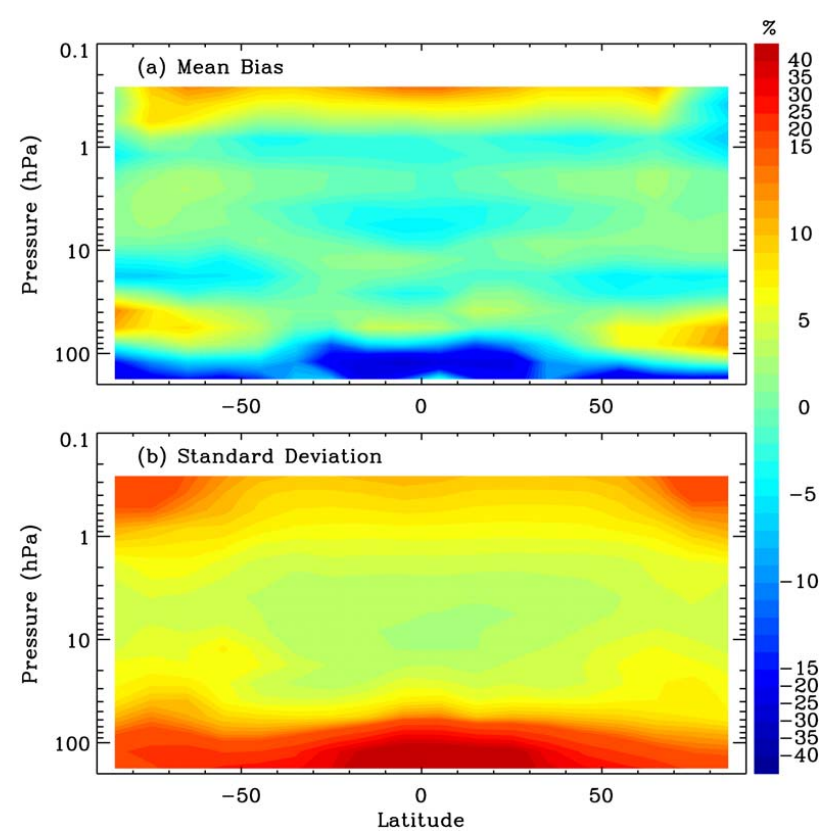

Fig. 4. Comparison between OMI and MLS retrievals (OMI MLS) as a function of latitude for 2006: (a) mean biases at each MLS layer and (b) $1 \sigma$ standard deviations of the differences. MLS profiles are not convolved with OMI retrieval averaging kernels.

Measurement), MIPAS (Michelson Interferometer for Passive Atmospheric Sounding), lidar, and ozonesonde observations (Jiang et al., 2007; Froidevaux et al., 2008). These smaller standard deviations are due in part to the close OMI/MLS collocation that significantly reduces the effect of geophysical variability on the comparison and partly to the high precision of OMI retrievals in the stratosphere. In addition, the standard deviations for the pressure $<0.7 \mathrm{hPa}$ are much smaller than the combined OMI/MLS precision, suggesting that the estimated MLS precision is overestimated for these altitude ranges. This OMI/MLS intercomparison demonstrates that OMI retrievals, despite having coarser vertical resolution, can be used to validate MLS and other stratospheric ozone measurements made even with higher vertical resolution than OMI. The excellent OMI/MLS agreement suggests that MLS data with higher vertical resolution and OMI data with high horizontal resolution and global coverage can be combined to study the spatiotemporal distribution of stratospheric ozone.

\subsection{Comparison of stratospheric ozone columns}

The lower boundary of $215 \mathrm{hPa}$ recommended for using MLS ozone, may be below or above the tropopause, depending on the location. For convenience, we use the $215 \mathrm{hPa}$ level as the effective "tropopause" for comparing with OMI SOC. MLS SOC is integrated from original MLS ozone profiles between $0.22-215 \mathrm{hPa}$, and is abbreviated as "SOC215"; the ozone column above $0.22 \mathrm{hPa}$, generally less than $0.1-0.2 \mathrm{DU}$, is
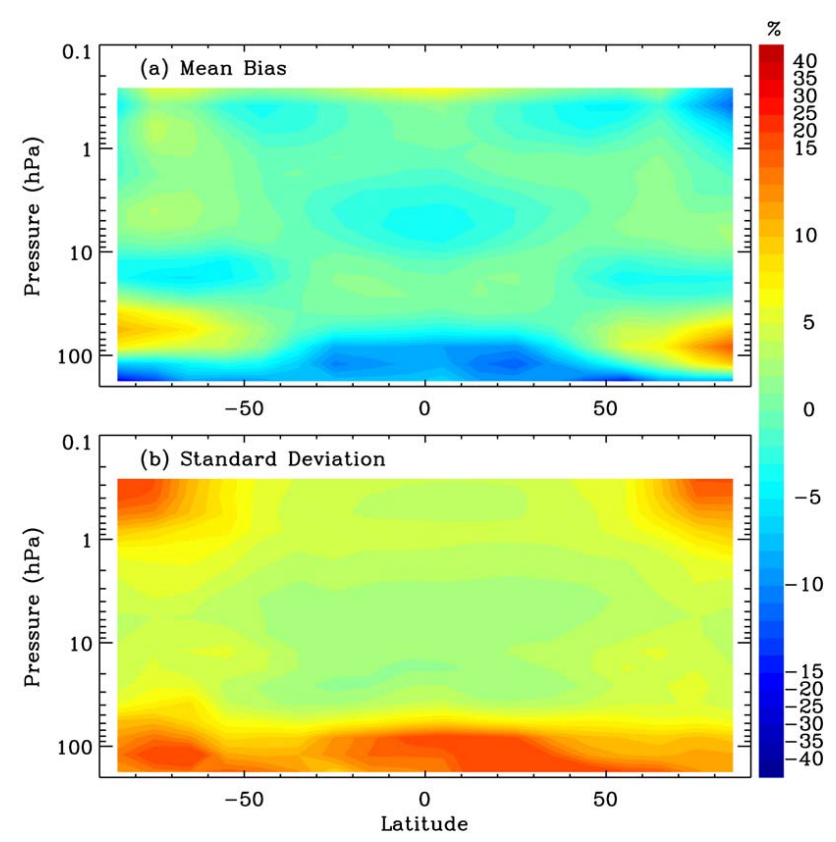

Fig. 5. Same as Fig. 4 except that MLS profiles are convolved with OMI retrieval averaging kernels.
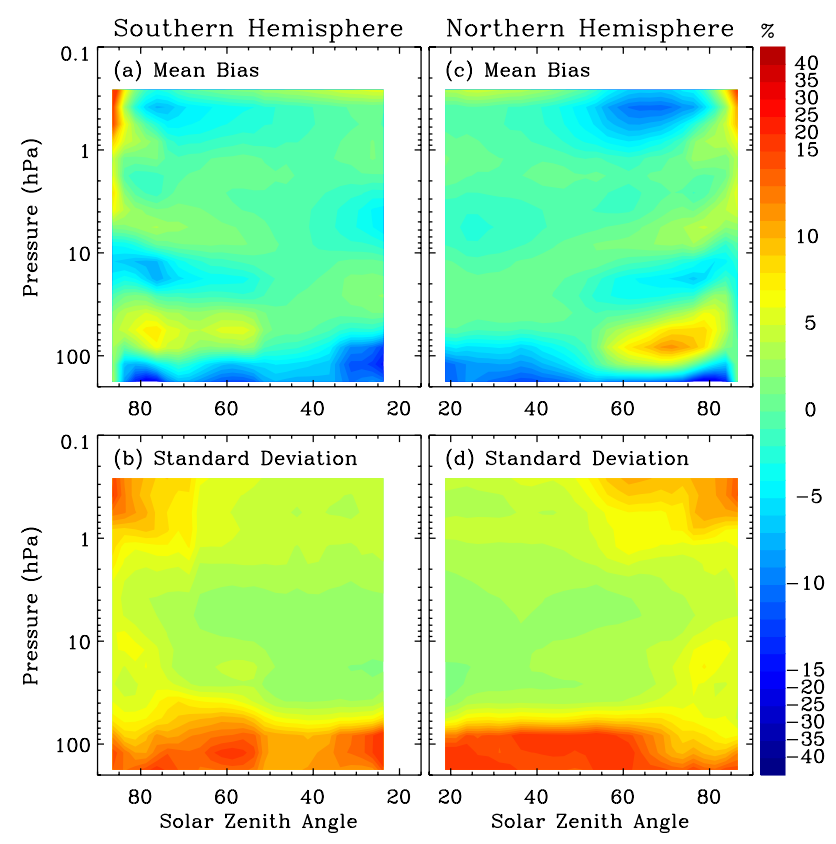

Fig. 6. Same as Fig. 5 except as a function of solar zenith angle in the Southern Hemisphere (a-b) and Northern Hemisphere (c-d), respectively.

negligible. OMI AKs are not applied here, because we want to determine whether SOC can be accurately derived from OMI data alone despite the coarser vertical resolution. OMI SOC215 is integrated from the top of the atmosphere to $215 \mathrm{hPa}$. 


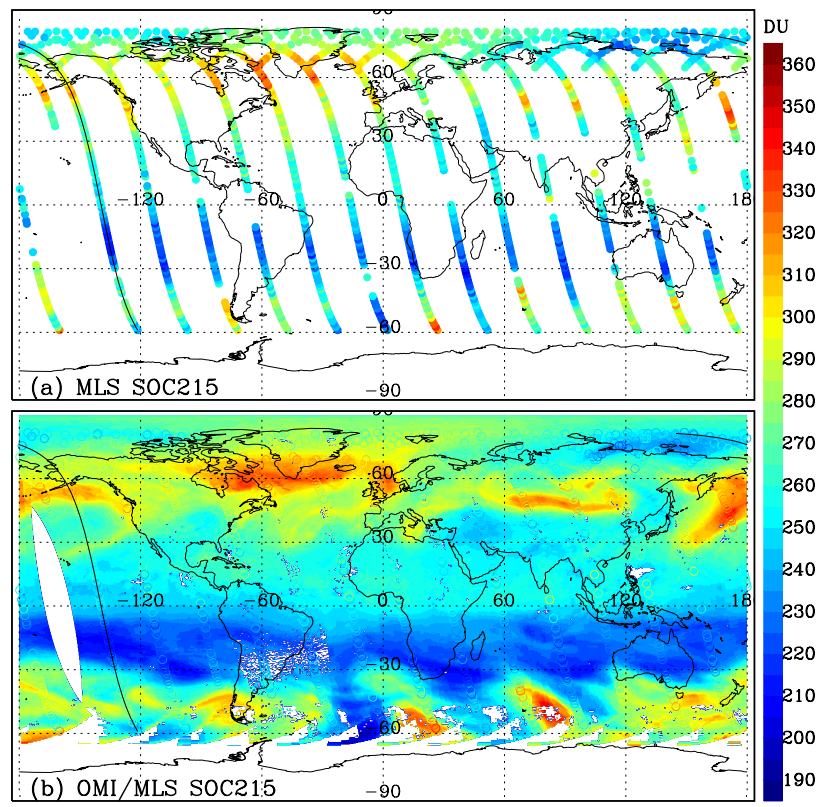

Fig. 7. (a) MLS stratospheric ozone column down to $215 \mathrm{hPa}$ (SOC215) on 11 June, 2006 (after data screening). (b) OMI SOC215 gridded onto $0.25^{\circ}$ longitude $\times 0.25^{\circ}$ latitude grid cells . MLS SOC215 is also overplotted (open circles). The solid line indicates the orbit shown in Fig. 8. Note that some systematic crosstrack position dependent biases have been removed before gridding by assuming zonal mean SOC215 within six days does not vary with the cross-track position. The blank area over South America is due to large fitting residuals caused by the South Atlantic Anomaly.

Figure 7 shows maps of both SOC215 from both OMI and MLS on 11 July 2006. We can see that OMI agrees very well with MLS data even in regions of large spatial variability (most MLS points invisible in Fig. 7b) except for some systematic positive biases in OMI data at northern high latitudes. Both OMI/MLS shows large spatial variability of ozone at the mid-latitudes, likely associated with synopticscale disturbances that affect ozone in the troposphere and lower stratosphere. Even between $5^{\circ} \mathrm{S}-5^{\circ} \mathrm{N}, \mathrm{SOC} 215$ shows large longitudinal variability of $20 \mathrm{DU}$ (difference between maximum and minimum SOC values at each latitude). The large variability in SOC shows that large TOC errors can occur even in the tropics when MLS is linearly interpolated to derive TOC on the daily basis using the TOR methods.

Figure 8 shows a detailed comparison of OMI and MLS SOC215 for the same orbit of retrievals as in Fig. 1 (also shown in Fig. 7). OMI and MLS data track each other very well, with a correlation coefficient of 0.97 . MLS SOC215 appears to have larger variability even in the tropics, which is consistent with the larger MLS uncertainty in SOC (4 DU or $2 \%$ ) than the retrieval errors in OMI SOC (1.5-4 DU or $0.7-2 \%)$. It could be argued that OMI retrievals cannot capture the actual SOC geophysical variability because OMI retrievals have much coarser vertical resolution and SOC AKs
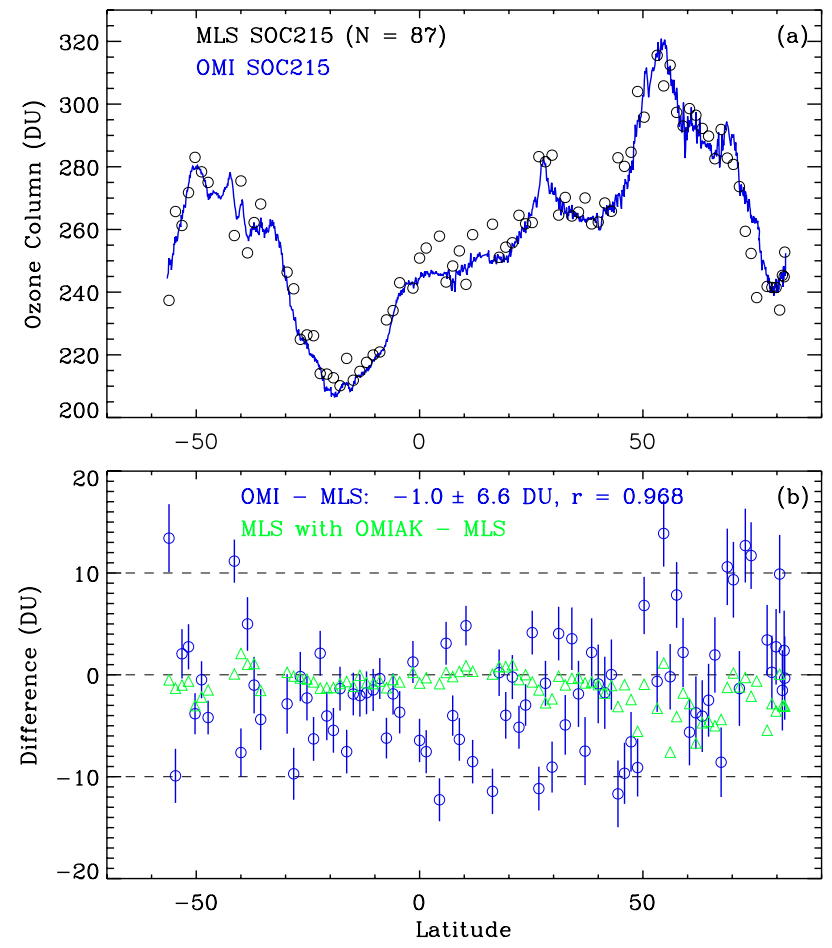

Fig. 8. (a) Comparison of OMI (blue line) stratospheric ozone column above $215 \mathrm{hPa}$ (SOC215) along the MLS track and MLS retrievals (black circles) for the same orbit as in Fig. 1 as a function of latitude. (b) The differences (circles) between collocated OMI and MLS SOC215 as well as the OMI smoothing errors (triangles) calculated by assuming MLS data as the truth. The error bars on the differences are statistical estimates of smoothing errors from OMI retrievals.

show significant sensitivity to ozone in the troposphere (Liu et al., 2010). Figure 8b shows that OMI/MLS SOC215 differences are generally within $10 \mathrm{DU}$, with a mean bias of $-1.0 \mathrm{DU}(-0.4 \%)$ and a standard deviation of $6.6 \mathrm{DU}$ $(2.5 \%)$. Based on the standard deviation and the precision of $2 \%$ in MLS SOC215, the retrieval errors or the sum of random-noise and smoothing errors in OMI SOC215 should be less than $1.5 \%$ (i.e., square root of $2.5^{2}-2^{2}$ ) because OMI/MLS systematic measurement errors, forward model and parameter errors, and geophysical variability also contribute to the standard deviation of the differences. The error bars in Fig. 8b also show that the statistical estimates of OMI retrieval errors (1.6-4 DU) (error bars) are generally much smaller than the differences. Furthermore, by assuming the high vertical resolution MLS data as the truth, we can directly estimate smoothing errors in OMI SOC215 (triangles). The estimated smoothing errors are mostly within a few DU except for several large values $(-7.6 \mathrm{DU}$ to $-4.0 \mathrm{DU})$, and most of them do not overlap with the differences. This suggests that OMI retrieval errors in SOC215 are quite small despite the coarser vertical resolution. According to Liu et al. (2010), the SOC AKs operate on the difference between 


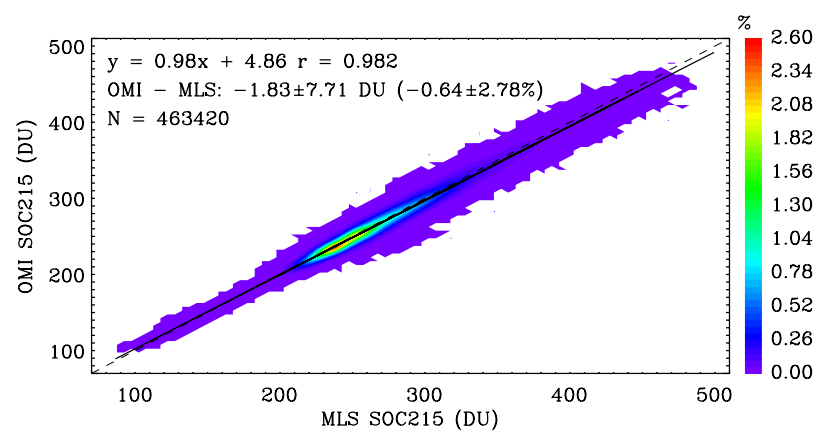

Fig. 9. Scatter density plot of OMI and coincident MLS stratospheric ozone column above $215 \mathrm{hPa}$ (SOC215) during 2006. Also shown are the linear regression line (solid) and the 1:1 line (dashed). The slope, offset, correlation, mean bias, and $1 \sigma$ standard deviation are given. The color scale shows the percentage of observations falling in 5 DU $\times 5$ DU areas.

true and a priori ozone profiles, so SOC smoothing errors depend on atmospheric ozone variability. Within atmospheric variability, the mean errors contributed from each layer to SOC smoothing errors are negligible in the middle and upper stratosphere and are generally within $2 \mathrm{DU}$ in the lower stratosphere and troposphere. Assuming errors are random and uncorrelated at each layer, the overall error, i.e., the root sum square of errors at individual layers is generally within 2-4 DU. The actual overall error is generally even smaller due to negative correlations between close layers.

Figure 9 shows a scatter density plot of all OMI and MLS SOC215 data. As for Fig. 7, OMI shows excellent agreement with MLS, with a correlation coefficient of 0.98 , and a slope of 0.98 . OMI shows a small negative bias $(-1.8 \mathrm{DU}$ or $-0.64 \%$ ), consistent with the validation that MLS SOC has positive biases relative to other data sets (Jiang et al., 2007; Froidevaux et al., 2008). The standard deviation is $7.7 \mathrm{DU}$ (2.78\%), less than the upper limit of the MLS SOC uncertainty estimate of $3 \%$. This supports the notion that the value of $3 \%$ is a conservative estimate for MLS SOC (Froidevaux et al., 2008). Similarly, assuming a precision of $2 \%$ for MLS SOC, we can deduce that the retrieval errors in OMI SOC215 are smaller than $1.9 \%$, even if other OMI and MLS errors and geophysical variability are neglected.

Figure 10 shows the SOC comparison as a function of latitude, and Fig. 11 shows the comparison as a function of SZA for the Southern and Northern Hemispheres, respectively. The mean biases are within 5.5 DU (2\%), but show some latitude/SZA dependence of up to $1.5 \%$ at SZA larger than $\sim 50^{\circ}$ and north of $50^{\circ} \mathrm{N}$, especially in the Northern Hemisphere (also shown in Fig. 7b). Although the profile bias patterns are somewhat symmetric between the two hemispheres, the mean biases in SOC215 show less latitude/SZA dependence in the Southern Hemisphere, due to different vertical distributions of ozone in the two hemispheres. The standard deviations of the mean biases are 5-10 DU (2.1-3.4\%)

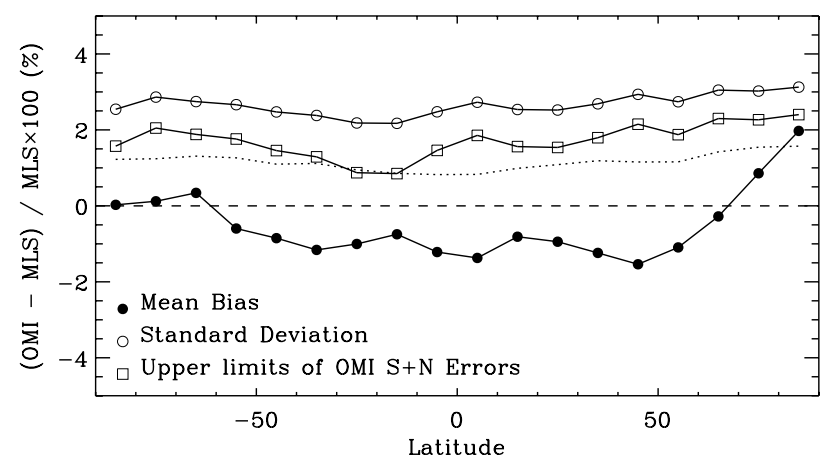

Fig. 10. Mean biases (solid circles) and $1 \sigma$ standard deviations of the differences (open circles) as a function of latitude. The open squares show the upper limit of combined smoothing and randomnoise errors in OMI SCO215 by assuming a precision of $2 \%$ for MLS SOC215 and the dotted line shows the average estimates of OMI smoothing and random-noise errors.

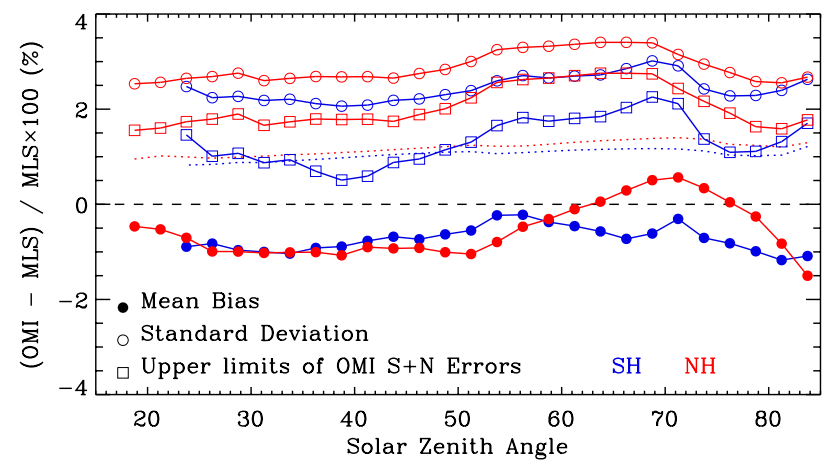

Fig. 11. Similar to Fig. 10 except as a function of solar zenith angle for the Southern Hemisphere (blue) and Northern Hemisphere (red), respectively.

with smaller values in the Southern Hemisphere. Assuming again a $2 \%$ precision for the MLS SOC, the upper limit of the OMI retrieval errors ranges from as low as $0.6 \%$ in the southern tropics (around SZA $40^{\circ}$ in Fig. 11) where there is less geophysical variability, to $2.8 \%$ in the northern middle latitudes. The dotted lines on Figs. 10-11 show the average OMI estimates of retrieval errors. These estimated errors exhibit much less latitude/SZA variability $(0.8-1.5 \%)$ and small hemispheric differences. The derived upper limits of OMI smoothing errors are generally larger than those OMI estimates especially in the Northern Hemisphere reflecting the large spatiotemporal variability in the Northern Hemisphere. The derived upper limits are even smaller at $\sim 20^{\circ} \mathrm{S}$ and SZA of $\sim 40^{\circ}$ in the Southern Hemisphere, which suggests the MLS SOC precision is likely smaller than 2\% (a precision of $1.9 \%$ is required to make the derived upper limits comparable to OMI error estimates). 
The small OMI SOC retrieval errors deduced from comparison with MLS data convincingly demonstrate that SOC can be accurately retrieved from OMI or similar UV measurements alone with retrieval errors comparable to or smaller than those from current MLS retrievals. This is contrary to the old paradigm that states that SOC can only be measured by a limb instrument to derive accurately the global distribution of TOC on a daily basis. Because OC can be derived more accurately from our retrieval algorithm than current OMI operational total ozone algorithms (due to the use of almost all the spectral information available in OMI UV spectra), this validation of OMI SOC implies that TOC can be accurately estimated from OMI data alone at high spatial resolution and with global coverage, without the need to use limb instruments to measure SOC and interpolation techniques to increase the spatial coverage of SOC.

\section{Summary and discussion}

We validate ozone profiles (in the pressure range 0.22 $215 \mathrm{hPa}$ ) retrieved from OMI ultraviolet radiances using one year of collocated Aura MLS data for 2006. OMI shows good agreement with MLS profiles, with mean biases less than $4 \%$ from $0.5-100 \mathrm{hPa}$, and positive biases of $5-10 \%$ above $0.5 \mathrm{hPa}$ and negative biases of $10-15 \%$ below $100 \mathrm{hPa}$. The standard deviations of the differences range from 4$6 \%$ between $1.5-32 \mathrm{hPa}$ to $36 \%$ below $32 \mathrm{hPa}$. The large standard deviations at low altitudes are dominated by OMI smoothing errors. After removing the smoothing errors, the mean biases are within $2.5 \%$ except for negative biases of 5-10\% below $100 \mathrm{hPa}$, and the standard deviations range from $3.5-5 \%$ range between $1-50 \mathrm{hPa}$ to $15 \%$ below $100 \mathrm{hPa}$. OMI retrievals show latitude and solar zenith angle dependent biases with respect to MLS data. However, the mean biases after accounting for OMI's coarser vertical resolution are mostly within $5 \%$ from $0.22-62 \mathrm{hPa}$, with negative biases of $8-16 \%$ at low altitudes and positive biases of $6-15 \%$ at high latitudes, and the standard deviations are mostly within 2-5\% except for the lower stratosphere and for the high latitude upper stratosphere, where the standard deviations are 919\%. Overall, OMI retrievals compare very well with MLS data, fgenerally within the combined uncertainty estimates.

This OMI/MLS intercomparison not only validates our OMI retrievals but also improves the validation of MLS retrievals. For example, the standard deviations of the OMI/MLS differences are significantly smaller than those between MLS and other correlative measurements used in MLS validation (Jiang et al., 2007; Froidevaux et al., 2008). This results partly from the close OMI/MLS collocation and partly from the high precision of OMI stratospheric ozone. This OMI/MLS intercomparison suggests that OMI retrievals can be used to augment the validation of MLS and other stratospheric ozone measurements.
We also validate Stratospheric Ozone Column (SOC) down to $215 \mathrm{hPa}$ (SOC215) with MLS data. OMI shows a small negative bias $(-1.8 \mathrm{DU}$ or $-0.6 \%)$, consistent with positive biases found in MLS SOC (Jiang et al., 2007; Froidevaux et al., 2008). The standard deviation is 7.7 DU (2.8\%), within the MLS precision estimate of $2-3 \%$. At different latitudes, the mean biases are within 5.5 DU (2\%); the standard deviations are 5-10 DU (2.1-3.4\%). Assuming a $2 \%$ precision for MLS SOC, we deduce that the upper limits of random noise and smoothing errors in OMI SOC range from $0.6 \%$ in the southern tropics to $2.8 \%$ in the northern middle latitudes.

Consistent estimates of small errors in OMI SOC clearly demonstrate that SOC can be derived accurately from OMI alone, with retrieval errors comparable to or even smaller than current MLS retrievals. Despite the coarser vertical resolution, the error contribution from each layer to SOC and the root sum square of error at individual layers are generally small based on atmospheric ozone variability. This implicitly supports our conclusion that TOC can be estimated accurately from OMI (or a similar nadir-viewing ultraviolet instrument) alone, preserving OMI's high spatial resolution and global coverage, and avoiding the need for limb measurements and spatial interpolation.

Acknowledgements. This study was supported by the NASA Atmospheric Composition Program (NNG06GH99G) and by the Smithsonian Institution. The Dutch-Finnish OMI instrument is part of the NASA EOS Aura satellite payload. The OMI Project is managed by NIVR and KNMI in the Netherlands. We acknowledge the OMI International Science Team and MLS science team for the satellite data used in this study.

Edited by: M. Dameris

\section{References}

Froidevaux, L., Jiang, Y. B., Lambert, A., Livesey, N. J., Read, W. G., Waters, J. W., Browell, E. V., Hair, J. W., Avery, M. A., McGee, T. J., Twigg, L. W., Sumnicht, G. K., Jucks, K. W., Margitan, J. J., Sen, B., Stachnik, R. A., Toon, G. C., Bernath, P. F., Boone, C. D., Walker, K. A., Filipiak, M. J., Harwood, R. S., Fuller, R. A., Manney, G. L., Schwartz, M. J., Daffer, W. H., Drouin, B. J., Cofield, R. E., Cuddy, D. T., Jarnot, R. F., Knosp, B. W., Perun, V. S., Snyder, W. V., Stek, P. C., Thurstans, R. P., and Wagner, P. A.: Validation of Aura Microwave Limb Sounder stratospheric ozone measurements, J. Geophys. Res., 113, D15S20, doi:10.1029/2007JD008771, 2008.

Jiang, Y. B., Froidevaux, L., Lambert, A., Livesey, N. J., Read, W. G., Waters, J. W., Bojkov, B., Leblanc, T., McDermid, I. S., Godin-Beekmann, S., Filipiak, M. J., Harwood, R. S., Fuller, R. A., Daffer, W. H., Drouin, B. J., Cofield, R. E., Cuddy, D. T., Jarnot, R. F., Knosp, B. W., Perun, V. S., Schwartz, M. J., Snyder, W. V., Stek, P. C., Thurstans, R. P., Wagner, P. A., Allaart, M., Andersen, S. B., Bodeker, G., Calpini, B., Claude, H., Coetzee, G., Davies, J., De Backer, H., Dier, H., Fujiwara, M., Johnson, B., Kelder, H., Leme, N. P., König-Langlo, G., Kyro, E., 
Laneve, G., Fook, L. S., Merrill, J., Morris, G., Newchurch, M., Oltmans, S., Parrondos, M. C., Posny, F., Schmidlin, F., Skrivankova, P., Stübi, R., Tarasick, D., Thompson, A., Thouret, V., Viatte, P., Vömel, H., von Der Gathen, P., Yela, M., and Zablocki, G.: Validation of Aura Microwave Limb Sounder Ozone by ozonesonde and lidar measurements, J. Geophys. Res., 112, D24S34, doi:10.1029/2007JD008776, 2007.

Levelt, P. F., van den Oord, G. H. J., Dobber, M. R., Malkki, A., Visser, H., de Vries, J., Stammes, P., Lundell, J. O. V., and Saari, H.: The Ozone Monitoring Instrument, IEEE T. Geosci. Remote, 44, 1093-1101, 2006.

Liu, X., Chance, K., Sioris, C. E., Spurr, R. J. D., Kurosu, T. P., Martin, R. V., and Newchurch, M. J.: Ozone profile and tropospheric ozone retrievals from Global Ozone Monitoring Experiment: Algorithm description and validation, J. Geophys. Res., 110, D20307, doi:10.1029/2005JD006240, 2005.

Liu, X., Bhartia, P. K., Chance, K., Spurr, R. J. D., and Kurosu, T. P.: Ozone profile retrievals from the Ozone Monitoring Instrument, Atmos. Chem. Phys., 10, 2521-2537, 2010, http://www.atmos-chem-phys.net/10/2521/2010/.

Livesey, N. J., Filipiak, M. J., Froidevaux, L., Read, W. G., Lambert, A., Santee, M. L., Jiang, J. H., Pumphrey, H. C., Waters, J. W., Cofield, R. E., Cuddy, D. T., Daffer, W. H., Drouin, B. J., Fuller, R. A., Jarnot, R. F., Jiang, Y. B., Knosp, B. W., Li, Q. B., Perun, V. S., Schwartz, M. J., Snyder, W. V., Stek, P. C., Thurstans, R. P., Wagner, P. A., Avery, M., Browell, E. V., Cammas, J. P., Christensen, L. E., Diskin, G. S., Gao, R. S., Jost, H. J., Loewenstein, M., Lopez, J. D., Nédélec, P., Osterman, G. B., Sachse, G. W., and Webster, C. R.: Validation of Aura Microwave Limb Sounder $\mathrm{O}_{3}$ and $\mathrm{CO}$ observations in the upper troposphere and lower stratosphere, J. Geophys. Res., 113, D15S02, doi:10.1029/2007JD008805, 2008.

McPeters, R. D., Labow, G. J., and Logan, J. A.: Ozone climatological profiles for satellite retrieval algorithms, J. Geophys. Res., 112, D05308, doi:10.1029/2005JD006823, 2007.

Rodgers, C. D.: Inverse methods for atmospheric sounding: Theory and practice, World Scientific Publishing, Singapore, 2000.

Schoeberl, M. R., Douglass, A. R., Hilsenrath, E., Bhartia, P. K., Beer, R., Waters, J. W., Gunson, M. R., Froidevaux, L., Gille, J. C., Barnett, J. J., Levelt, P. F., and de Cola, P.: Overview of the EOS Aura Mission, IEEE T. Geosci. Remote, 44, 1066-1074, 2006.
Schoeberl, M. R., Ziemke, J. R., Bojkov, B., Livesey, N., Duncan, B., Strahan, S., Froidevaux, L., Kulawik, S., Bhartia, P. K., Chandra, S., Levelt, P. F., Witte, J. C., Thompson, A. M., Cuevas, E., Redondas, A., Tarasick, D. W., Davies, J., Bodeker, G., Hansen, G., Johnson, B. J., Oltmans, S. J., Vömel, H., Allaart, M., Kelder, H., Newchurch, M., Godin-Beekmann, S., Ancellet, G., Claude, H., Andersen, S. B., Kyr, E., Parrondos, M., Yela, M., Zablocki, G., Moore, D., Dier, H., von der Gathen, P., Viatte, P., Stübi, R., Calpini, B., Skrivankova, P., Dorokhov, V., de Backer, H., Schmidlin, F. J., Coetzee, G., Fujiwara, M., Thouret, V., Posny, F., Morris, G., Merrill, J., Leong, C. P., Koenig-Langlo, G., and Joseph, E.: A trajectory-based estimate of the tropospheric ozone column using the residual method, J. Geophys. Res., 112, D24S49, doi:10.1029/2007JD008773, 2007.

Stajner, I., Wargan, K., Pawson, S., Hayashi, H., Chang, L.-P., Hudman, R. C., Froidevaux, L., Livesey, N., Levelt, P. F., Thompson, A. M., Tarasick, D. W., Stübi, R., Andersen, S. B., Yela, M., König-Langlo, G., Schmidlin, F. J., and Witte, J. C.: Assimilated ozone from EOS-Aura: Evaluation of the tropopause region and tropospheric columns, J. Geophys. Res., 113, D16S32, doi:10.1029/2007JD008863, 2008.

Waters, J. W., Froidevaux, L., Harwood, R. S., Jarnot, R. F., Pickett, H. M., Read, W. G., Siegel, P. H., Cofield, R. E., Filipiak, M. J., Flower, D. A., Holden, J. R., Lau, G. K., Livesey, N. J., Manney, G. L., Pumphrey, H. C., Santee, M. L., Wu, D. L., Cuddy, D. T., Lay, R. R., Loo, M. S., Perun, V. S., Schwartz, M. J., Stek, P. C., Thurstans, R. P., Boyles, M. A., Chandra, K. M., Chavez, M. C., Chen, G. S., Chudasama, B. V., Dodge, R., Fuller, R. A., Girard, M. A., Jiang, J. H., Jiang, Y., Knosp, B. W., Labelle, R. C., Lam, J. C., Lee, A. K., Miller, D., Oswald, J. E., Patel, N. C., Pukala, D. M., Quintero, O., Scaff, D. M., Vansnyder, W., Tope, M. C., Wagner, P. A., and Walch, M. J.: The Earth Observing System Microwave Limb Sounder (EOS MLS) on the Aura Satellite, IEEE T. Geosci. Remote, 44, 1075-1092, 2006.

Yang, Q., Cunnold, D. M., Wang, H. J., Froidevaux, L., Claude, H., Merrill, J., Newchurch, M., and Oltmans, S. J.: Midlatitude tropospheric ozone columns derived from the Aura Ozone Monitoring Instrument and Microwave Limb Sounder measurements, J. Geophys. Res., 112, D20305, doi:10.1029/2007JD008528, 2007.

Ziemke, J. R., Chandra, S., Duncan, B. N., Froidevaux, L., Bhartia, P. K., Levelt, P. F., and Waters, J. W.: Tropospheric ozone determined from Aura OMI and MLS: Evaluation of measurements and comparison with the Global Modeling Initiative's Chemical Transport Model, J. Geophys. Res., 111, D19303, doi:10.1029/2006JD007089, 2006. 